\title{
Full Kinetics and a Mechanistic Investigation of the Green Protocol for Synthesis of $\beta$-Aminoketone in the Presence of Saccharose as a Catalyst by a One-Pot Three-Component Reaction
}

\author{
Sayyed Mostafa Habibi-Khorassani, Malek Taher Maghsoodlou, \\ Mehdi Shahraki, Sadegh Talaie Far, and Mir Rasul Mousavi \\ Department of Chemistry, Faculty of Science, University of Sistan and Baluchestan, P.O. Box 98135-674, Zahedan 9816658514, Iran \\ Correspondence should be addressed to Mehdi Shahraki; mehdishahraki@chem.usb.ac.ir
}

Received 29 January 2014; Revised 2 May 2014; Accepted 3 May 2014; Published 16 June 2014

Academic Editor: Taicheng An

Copyright (C) 2014 Sayyed Mostafa Habibi-Khorassani et al. This is an open access article distributed under the Creative Commons Attribution License, which permits unrestricted use, distribution, and reproduction in any medium, provided the original work is properly cited.

\begin{abstract}
For the first time, in a green protocol, an investigation of the kinetics and mechanism of the reaction between benzaldehyde $\mathbf{1}$, 4-chloroanilinne 2, and acetophenone 3 compounds in the presence of saccharose as a catalyst was performed for generating $\beta$-aminoketone. For determining the kinetic parameters, the reaction was monitored by using the UV/Vis spectrophotometry technique. The second order rate constant $\left(k_{1}\right)$ was automatically calculated by the standard equations contained within the program. In the studied temperature range, the second order rate constant $\left(\ln k_{1}, \ln k_{1} / T\right)$ depended on reciprocal temperature that was in good consistent with Arrhenius and Eyring equations, respectively. These data provided the suitable plots for calculating the activation energy and parameters $\left(E a, \Delta G^{\ddagger}, \Delta S^{\ddagger}\right.$, and $\left.\Delta H^{\ddagger}\right)$ of the reaction. Furthermore, useful information was obtained from studying the effects of solvent, concentration, and catalyst on the reaction mechanism. The results showed that the first step of the reaction mechanism is a rate determining step (RDS). The obtained experimental data and also the steady state assumption confirmed the proposed mechanism.
\end{abstract}

\section{Introduction}

Mannich reaction is as one of the most important carboncarbon bond forming reactions in organic synthesis [1]. The products of Mannich reaction are mainly $\beta$-Amino carbonyl compounds and their derivatives are mainly products of Mannich reactions and significant synthetic intermediates for various pharmaceuticals and natural products [2-6].

Over the past decades, the research on the new operationally simple, efficient, recyclable, and environmentally benign catalysts for the Mannich reaction has gained popularity in synthetic chemistry. Nowadays, it has been noted that this reaction can also be promoted by a wide array of catalysts, such as rare earth perfluorooctanoate $\left(\mathrm{RE}(\mathrm{PFO})_{3}\right)$ [7], Brönsted acidic ionic liquid [8], $\mathrm{HClO}_{4}-\mathrm{SiO}_{2}$ [9], SalenZn complex [10], cerium (IV) ammonium nitrate (CAN) [11],
Triton X10 (TX10) aqueous micelles [12], $\mathrm{CeCl}_{3} \cdot 7 \mathrm{H}_{2} \mathrm{O}$ [13], Tröger's base derivatives [14], Cbz protected [15], and PEG$\mathrm{OSO}_{3} \mathrm{H}$ [16-30]. However, they often suffer from the drawbacks of long reaction times, harsh reaction conditions, toxicity, and difficulty in product separation, which limit their use in the synthesis of complex molecules. Hence, development of a synthetic protocol that is nature friendly, simple, efficient, and cost effective remains an ever challenging objective. One of these methods uses organocatalysis for C-C bond formation [31] and synthesis of important compounds such as highly functionalized piperidines [32]. Beyond doubt, organocatalysis belongs to the most exciting and innovative chapters of organic chemistry today [31]. Herein our research group presents entirely green protocol, an eco-friendly, simple, and efficient protocol for synthesis of $\beta$-amino carbonyl compounds via a one-pot three-component reaction 
among aromatic aldehydes, anilines, and acetophenone in the presence of saccharose as catalyst in water/ethanol at room temperature (Figure 1). It was noteworthy that the results of this work have been published recently [33]. Kinetics studies of these reactions are therefore important, but they have not yet been investigated. To fully understand or apply any chemical reaction, we must know more than just the identities of the reactants and the products. We must know, if the reaction will occur (is it thermodynamically favorable?), how long it will take to occur (is it kinetically feasible?). For a complete understanding, we should also know how it occurs. Hence, we now describe full kinetics and mechanistic of mentioned reaction in later section. The activation energy and the other related thermodynamic parameters for the reaction are experimentally determined through the Arrhenius and Eyring equations. Numerous kinetic investigations over a large area of different reactions have previously been reported using the UV/Vis technique [34-47].

\section{Method}

2.1. Kinetics. For further insight into the reaction mechanism between benzaldehyde 1, 4-chloroanilinne 2, and acetophenone compound $\mathbf{3}$ in the presence of saccharose as a catalyst, a kinetics study of the reaction was performed using the UV/Vis spectrophotometry technique. Firstly, it was necessary to find the suitable wavelength for the kinetic study of the reaction. For this reason in the first experiment, $10^{-2} \mathrm{M}$ solution of each compound 1,2 , and 3 and $1.5 \times 10^{-2} \mathrm{M}$ solution of saccharose were prepared in a mixture of water and ethanol $(50: 50)$ as solvent. The relevant spectrum of each compound was recorded over the wavelength range 200$500 \mathrm{~nm}$. Figures 2, 3, 4, and 5 exhibit the ultraviolet spectra of compounds 1, 2, and 3 and saccharose, respectively. In the second experiment, the reaction mixture was started into a $10 \mathrm{~mm}$ quartz spectrophotometer cell along with a $10^{-2} \mathrm{M}$ solution of each compound $(1,2$, and 3$)$ and $1.5 \times 10^{-2} \mathrm{M}$ saccharose according to stoichiometry of each compound in the overall reaction. The reaction was monitored by conducting scans of the entire spectrum with 10 -second intervals during the whole reaction time at ambient temperature. The ultraviolet spectra shown in Figure 6 are typical. Herein, the upward of direction of the arrow indicates the progress of product versus time. From this, the appropriate wavelength was discovered to be 365,375 , and $380 \mathrm{~nm}$. Since, at these wavelengths, compounds $\mathbf{1}, \mathbf{2}$, and $\mathbf{3}$ and saccharose have relatively no absorbance value, it gave us the chance to find the practical conditions that allows kinetics and a mechanistic investigation of the reaction. Herein, in all the experiments, the UV/Vis spectrum of the compound product was measured over the concentration range $\left(10^{-3} \mathrm{M} \leq \mathrm{M}\right.$ product $\left.\leq 10^{-2} \mathrm{M}\right)$ to confirm a linear relationship between the absorbance and concentrations values.

In the third experiment under same concentration of each compound $\left(10^{-2} \mathrm{M}\right)$, experimental absorbance curve was recorded versus time at $25^{\circ} \mathrm{C}$ temperature and the biggest absorption wavelength $375 \mathrm{~nm}$. This is shown in Figure 7 (dotted line) which exactly fits to second order fitting curve (solid line). In this case, overall order of rate low

$$
\left(\text { rate }=k_{\text {ovr }}[1]^{\alpha}[2]^{\beta}[3]^{\gamma}[\text { Cat }]\right)
$$

can be written as $\alpha+\beta+\gamma=2$. It is obvious that the reaction is second order. Then, the rate constant $\left(74.62 \mathrm{~min}^{-1} \cdot \mathrm{M}^{-1}\right)$ of the reaction was automatically calculated by the software [48] associated within the UV/Vis equipment.

\section{Results and Discussion}

3.1. Effect of Solvent and Temperature. In order to determine the effect of change in temperature and solvent environment change on the reaction rate, various experiments were arranged with different temperatures and solvent polarity under the same conditions with the previous experiment. For this purpose, a mixture of methanol and water (methanol/water, 4:1) and a mixture of ethanol and water (ethanol/water, 1:1) have been used in the experiment. The results showed that rate of reaction speeds up in solvent with high dielectric constant (ethanol and water) with respect to lower dielectric constant (methanol/water, $4: 1$ ) at all temperatures investigated (see Table 1).

As can be seen in Table 1, increasing the temperature increases reaction rate in all solvents. In the studied temperature range, the second order equation rate constant $\left(\ln k_{1}\right)$ of the reaction was inversely proportional to the temperature, which is in agreement with the Arrhenius equation. This behavior is shown in Figure 8. The activation energy for the reaction between $\mathbf{1}, \mathbf{2}$, and 3 was obtained $\left(35.85 \mathrm{~kJ} \cdot \mathrm{mol}^{-1}\right)$ from the slope of Figure 8 .

3.2. Effect of Concentration. In order to obtain a partial order of reaction regarding benzaldehydel, pseudoorder conditions were performed for the reaction. So in the fourth experiment, we followed the reaction kinetics by plotting the UV/Vis absorbance versus time at wavelength $375 \mathrm{~nm}$ for the $10^{-3} \mathrm{M}$, $10^{-2} \mathrm{M}$, and $10^{-2} \mathrm{M}$ solution of each compound $(\mathbf{1}, 2$, and 3 ), respectively, at $25.0^{\circ} \mathrm{C}$ along with $10^{-2} \mathrm{M}$ solution of saccharose. For this case, the rate law can be expressed as

$$
\begin{gathered}
\text { rate }=k_{\mathrm{ovr}}[\mathbf{1}]^{\alpha}[2]^{\beta}[3]^{\gamma}[\mathrm{Cat}] \\
\text { rate }=k_{\mathrm{obs}}[\mathbf{1}]^{\alpha}, \\
k_{\mathrm{obs}}=k_{\mathrm{ovr}}[2]^{\beta}[3]^{\gamma}[\mathrm{Cat}] .
\end{gathered}
$$

The infinity absorbance (A), which is the absorbance at reaction completion, is obtainable from Figure 9 at $t=$ $30 \mathrm{~min}$. With respect to this value, the zero, first, or second curve fittings can be drawn automatically for the reaction using the software [48] associated with the UV/Vis instrument. The original experimental absorbance against time data made a first pseudoorder available fit curve (solid line) at wavelength $375 \mathrm{~nm}$, which exactly fits the experimental curve (dotted line) displayed in Figure 9 as a typical. Herein, observation rate constant $\left(k_{\text {obs }}\right)$ was automatically calculated by (II) which has been defined in the software program. It is 


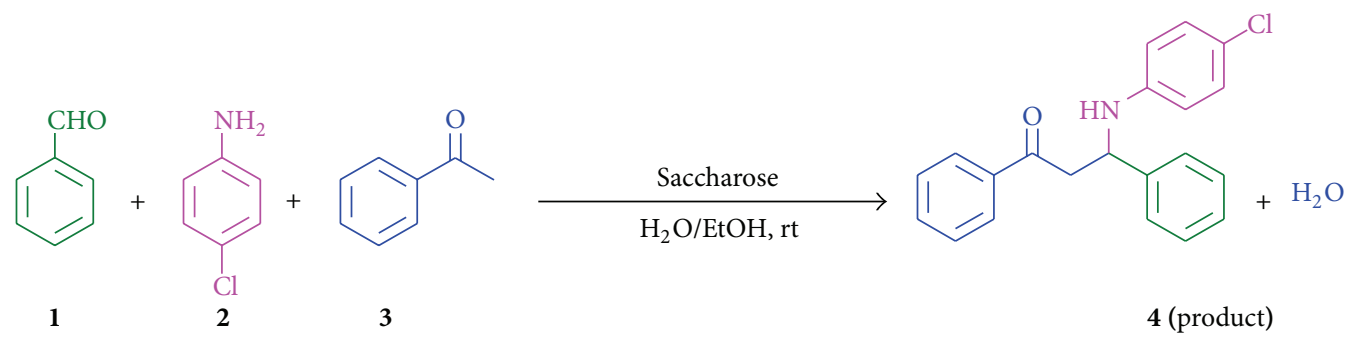

FIGURE 1: Synthesis of $\beta$-aminoketone 4.

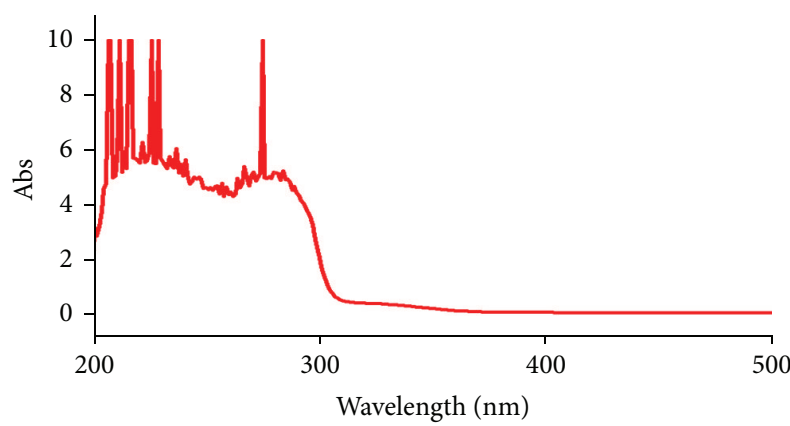

Figure 2: The UV/Vis spectrum of $10^{-2} \mathrm{M}$, benzaldehyde compound 1 in a mixture of water and ethanol $(50: 50)$.

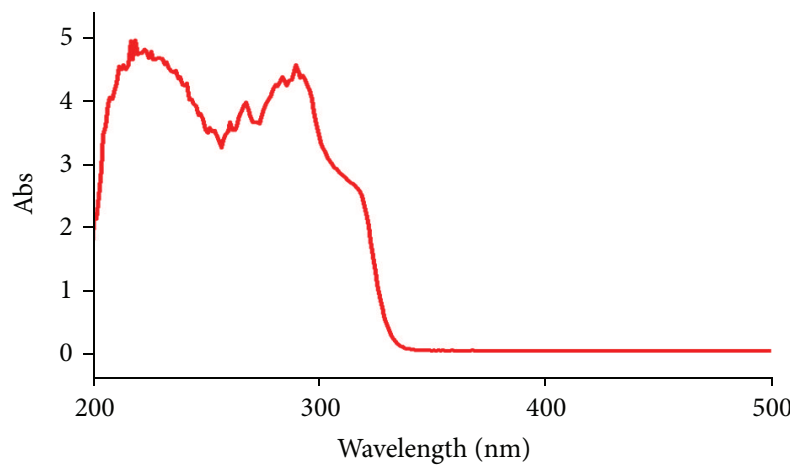

FIgURE 3: The UV/Vis spectrum of $10^{-2} \mathrm{M}$, 4-chloroanilinne compound 2 in a mixture of water and ethanol $(50: 50)$.

obvious that the reaction is of the first order type with respect to benzaldehyde $1 ; \alpha=1$.

Also to gain a partial order of reaction with respect to 4-chloroanilinne $2,\left(10^{-3} \mathrm{M}\right)$, under pseudoorder condition, compounds 3 and 1 were used in excess $\left(10^{-2} \mathrm{M}\right)$. Same procedure was employed as a previous experiment. The rate low can be written as

$$
\begin{gathered}
\text { rate }=k_{\mathrm{ovr}}[\mathbf{1}]^{a}[2]^{b}[3]^{g}[\mathrm{Cat}] \quad \text { or rate }=k_{\mathrm{obs}}[2]^{\mathrm{b}}, \\
k_{\mathrm{obs}}=k_{\mathrm{ovr}}[3]^{g}[\mathbf{1}]^{a}[\mathrm{Cat}] .
\end{gathered}
$$

The original experimental absorbance (solid line) against time data (Figure 10) creates a first order fit curve (full line) at $370 \mathrm{~nm}$, which fits the experimental curve precisely. Therefore, the reaction is of the first order type in relation to the 4-chloroanilinne $2 ; \beta=1$.

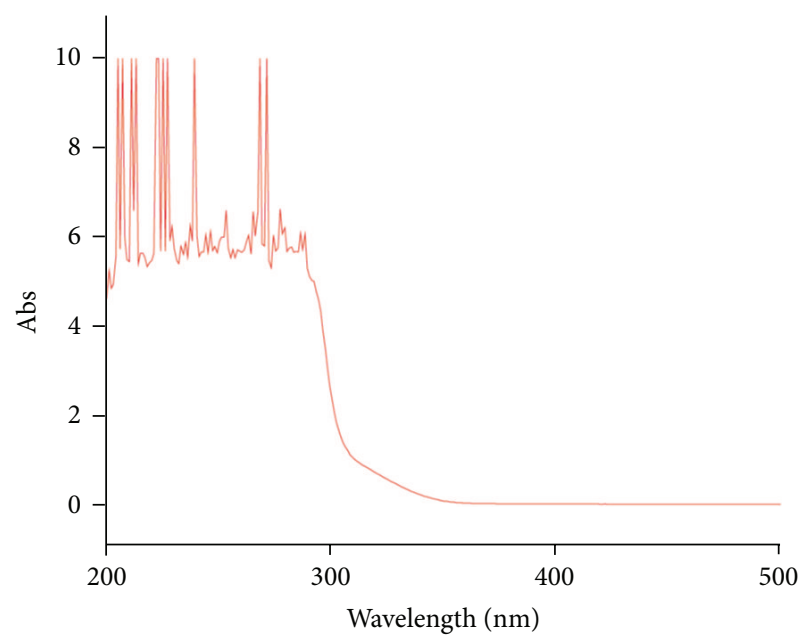

FIGURE 4: The UV/Vis spectrum of $10^{-2} \mathrm{M}$, acetophenone compound 3 in a mixture of water and ethanol $(50: 50)$.

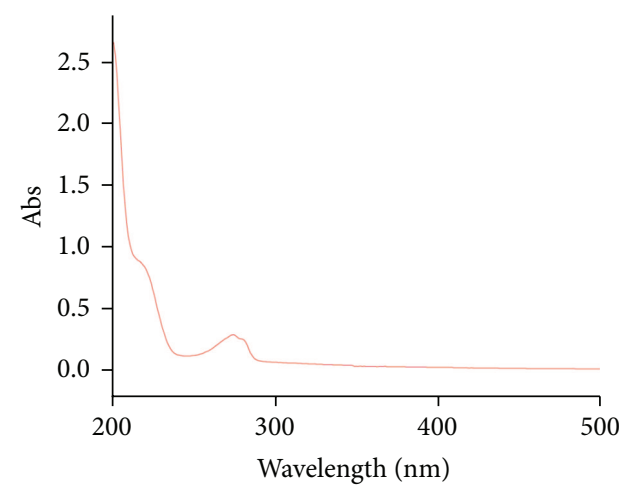

FIgURE 5: The UV/Vis spectrum of $10^{-2} \mathrm{M}$, saccharose as a catalyst in a mixture of water and ethanol $(50: 50)$.

In the fifth experiment, the reaction was followed in the presence of an excess of compounds 1 and $2\left(10^{-2} \mathrm{M}\right.$ of each) along with $10^{-3} \mathrm{M}$ of compound 3 , so the rate low can be expressed as

$$
\begin{gathered}
\text { rate }=k_{\mathrm{ovr}}[1]^{\alpha}[2]^{\beta}[3]^{\gamma}[\mathrm{Cat}], \\
\text { rate }=k_{\mathrm{obs}}[3]^{\gamma}, \\
k_{\mathrm{obs}}=k_{\mathrm{ovr}}[1]^{\alpha}[2]^{\beta}[\mathrm{Cat}] .
\end{gathered}
$$


TABLE 1: Rate constants for the reaction between $\mathbf{1}\left(10^{-2} \mathrm{M}\right), \mathbf{2}\left(10^{-2} \mathrm{M}\right)$, and $\mathbf{3}\left(10^{-2} \mathrm{M}\right)$ in the presence of saccharose as a catalyst and both solvents containing a mixture of methanol and water (methanol/water, $4: 1)$ and a mixture of ethanol and water $(1: 1)$.

\begin{tabular}{|c|c|c|c|c|c|}
\hline \multirow{2}{*}{ Solvent } & \multirow{2}{*}{$\varepsilon$} & \multicolumn{4}{|c|}{$k_{1} \times 10^{2}\left(\mathrm{~min}^{-1} \cdot \mathrm{M}^{-1}\right)$} \\
\hline & & $T=20^{\circ} \mathrm{C}$ & $T=25^{\circ} \mathrm{C}$ & $T=30^{\circ} \mathrm{C}$ & $T=35^{\circ} \mathrm{C}$ \\
\hline Methanol: water, $4: 1$ & 42.08 & 9.084 & 16.64 & 24.18 & 31.71 \\
\hline Ethanol: water, $1: 1$ & 52.12 & 36.85 & 49.74 & 62.64 & 75.53 \\
\hline
\end{tabular}

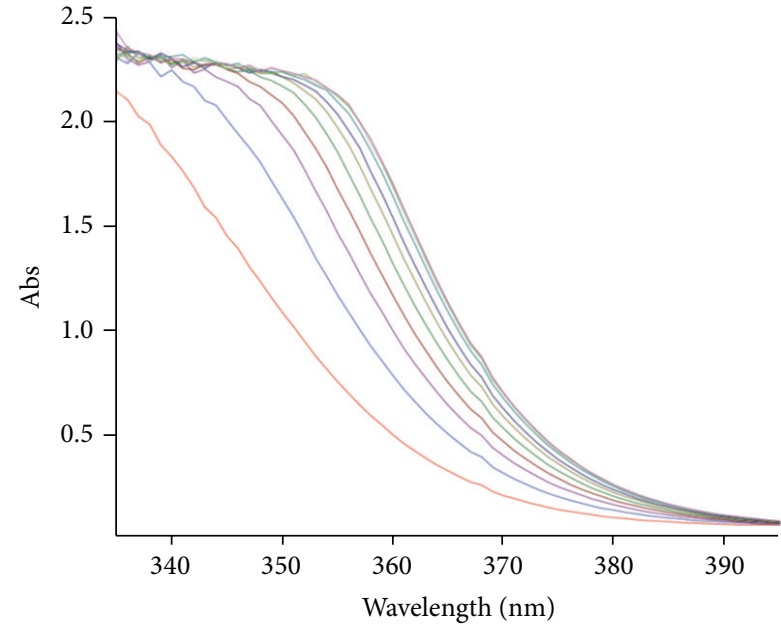

FIGURE 6: The UV/Vis spectra of the reaction between benzaldehyde $\mathbf{1}\left(10^{-2} \mathrm{M}\right)$, 4-chloroanilinne $2\left(10^{-2} \mathrm{M}\right)$, and acetophenone $3\left(10^{-2} \mathrm{M}\right)$ in the presence of saccharose as a catalyst in a mixture of water and ethanol $(50: 50)$, and reaction proceeds into a $10 \mathrm{~mm}$ light-path cell. The upward of direction of the arrow indicates the progress of product versus time.

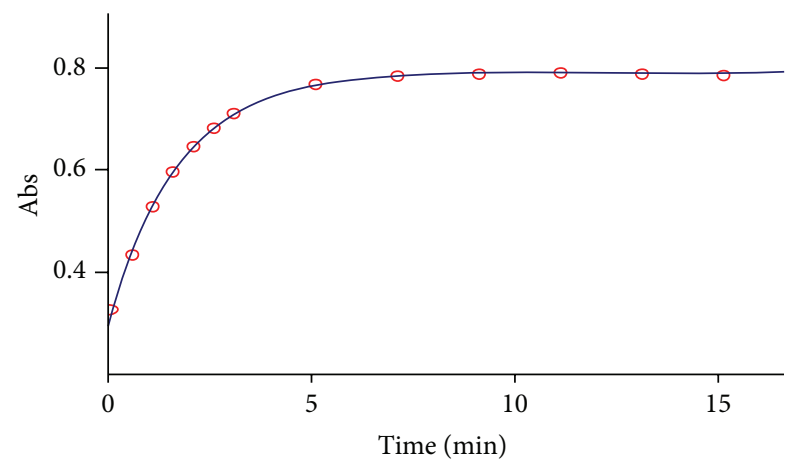

FIGURE 7: The experimental absorbance change (dotted line) along with the fit curve (solid line) against time for the reaction between benzaldehyde $1\left(10^{-2} \mathrm{M}\right)$, 4-chloroanilinne $2\left(10^{-2} \mathrm{M}\right)$, and acetophenone $3\left(10^{-2} \mathrm{M}\right)$ in a mixture of water and ethanol $(50: 50)$ at $375 \mathrm{~nm}$ and $25.0^{\circ} \mathrm{C}$.

The experimental absorbance curve (dotted line) versus times was recorded at $25^{\circ} \mathrm{C}$ and wavelength $375 \mathrm{~nm}$ (Figure 11). Then, the rate constant $\left(k=74.24 \mathrm{~min}^{-1} \cdot \mathrm{M}^{-1}\right)$ of the reaction was automatically obtained by the software program. The value of the rate constant was similar to that of the pervious experiment (Figure 7, for this case, concentration of each compound is same corresponding to $10^{-2} \mathrm{M}$ ). This curve led

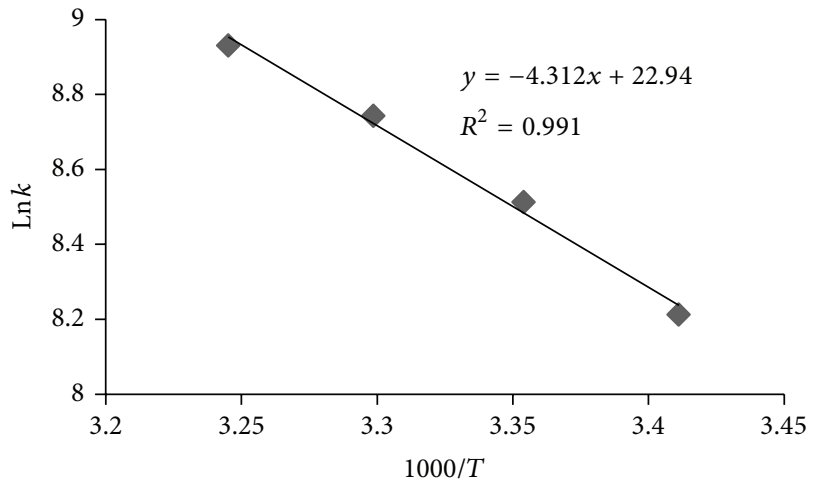

Figure 8: The dependence of the second order rate constant $\left(\ln k_{1}\right)$ on reciprocal temperature for the reaction between compounds $\mathbf{1}, \mathbf{2}$, and 3 measured at a wavelength of $375 \mathrm{~nm}$ in a mixture of water and ethanol (50:50), according to the Arrhenius equation.

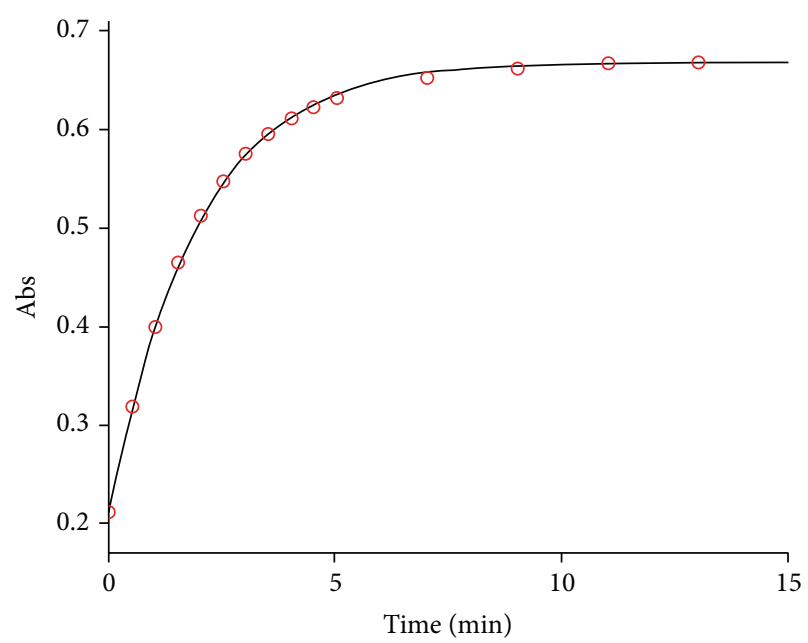

FIGURE 9: First pseudo order fit curve (solid line) along with the original experimental curve (dotted line) in relation to benzaldehyde $\mathbf{1}\left(10^{-3} \mathrm{M}\right)$, for the reaction between $\mathbf{1}\left(10^{-3} \mathrm{M}\right), \mathbf{2}\left(10^{-2} \mathrm{M}\right)$ and $3\left(10^{-2} \mathrm{M}\right)$ which was processed in a mixture of water and ethanol $(50: 50)$ at $375 \mathrm{~nm}$.

to similar fit curve and rate constant. In fact, the experimental data indicated that the second order rate constant $(k=$ $74.6 \mathrm{~min}^{-1} \cdot \mathrm{M}^{-1}$, Figure 7) of this reaction under mentioned condition in (I) (page 7, $10^{-2} \mathrm{M}$ concentration of each compound) is equal to the second order rate constant $\left(k_{\text {over }}=\right.$ $74.2 \mathrm{~min}^{-1} \cdot \mathrm{M}^{-1}$, Figure 11), (equation (IV), $10^{-2} \mathrm{M}$ of each compound (1 and 2 ) and $10^{-3} \mathrm{M}$ of compound 3 ) under fifth experiment. This is possible when $\gamma$ is zero in both (I) and 


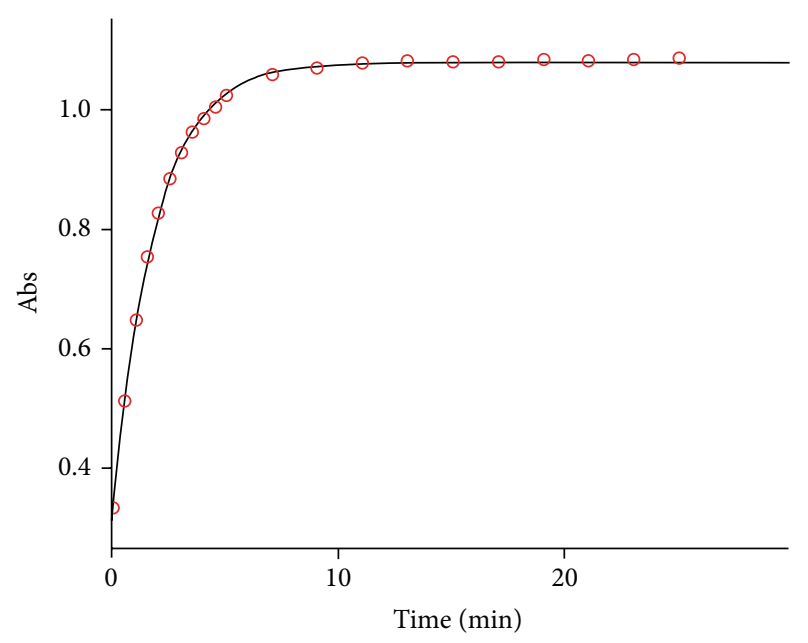

FIGURE 10: First pseudoorder fit curve (solid line) accompanied by the original experimental curve (dotted line) with respect to 4chloroanilinne $2\left(10^{-3} \mathrm{M}\right)$, for the reaction between $\mathbf{1}\left(10^{-2} \mathrm{M}\right), \mathbf{3}$ $\left(10^{-2} \mathrm{M}\right)$, and $2\left(10^{-3} \mathrm{M}\right)$, which proceeded in a mixture of water and ethanol $(50: 50)$.

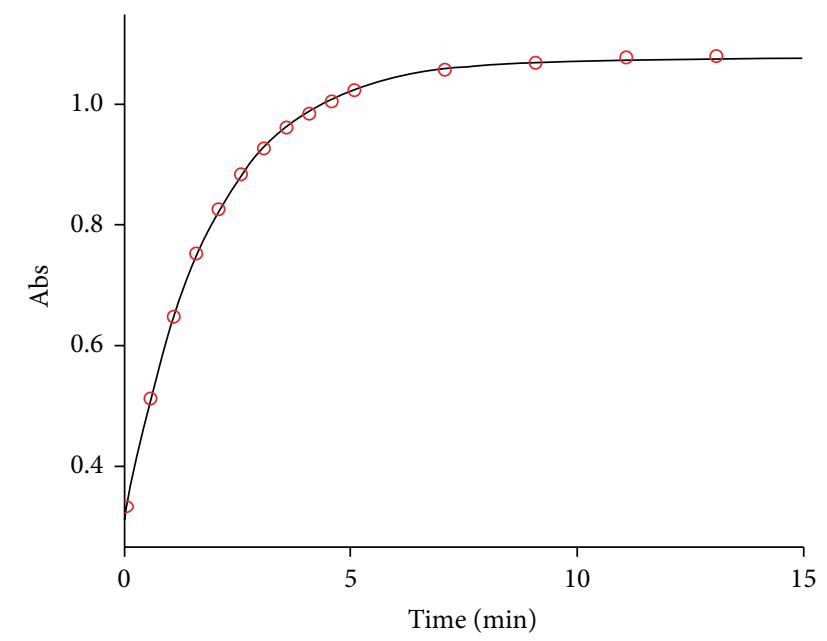

FIGURE 11: Second pseudoorder fit curve (solid line) along with the original experimental curved (dotted) for the reaction between benzaldehyde $1\left(10^{-2} \mathrm{M}\right)$, 4-chloroanilinne $2\left(10^{-2} \mathrm{M}\right)$, and acetophenone $3\left(10^{-3} \mathrm{M}\right)$, at $375 \mathrm{~nm}, 25.0^{\circ} \mathrm{C}$ in a mixture of water and ethanol $(50: 50)$.

(IV). It means that the reaction is zero and of the second order type in relation to compound $\mathbf{1}$ and sum of $\mathbf{2}$ and $\mathbf{3}(\alpha+\beta=2)$, respectively. As a result, the overall order of reaction is two that is same with the previous experiment (third experiment, page 7 ).

Utilizing the above mentioned results, the simplified scheme of the proposed reaction mechanism (Figure 12, [33]) is shown in Figure 13.

To investigate which step of the proposed mechanism is the rate-determining step, the rate law was written using the final step of reaction (Figure 13)

$$
\text { rate }=k_{5}\left[\mathrm{I}_{2}\right]\left[\mathrm{I}_{4}\right][\mathrm{Cat}] \text {. }
$$

The steady state approximation can be applied for obtaining the concentration of $\left[\mathrm{I}_{2}\right]$ which is generated from the following equations:

$$
\begin{gathered}
\frac{\mathrm{d}\left[\mathrm{I}_{2}\right]}{\mathrm{dt}}=k_{2}\left[\mathrm{I}_{1}\right][\mathrm{Cat}]-k_{5}\left[\mathrm{I}_{2}\right]\left[\mathrm{I}_{4}\right][\mathrm{Cat}]=0, \\
k_{2}\left[\mathrm{I}_{1}\right][\mathrm{Cat}]=k_{5}\left[\mathrm{I}_{2}\right]\left[\mathrm{I}_{4}\right][\mathrm{Cat}] .
\end{gathered}
$$

The value of (VI) can be replaced in (V) so the rate equation becomes

$$
\text { rate }=k_{2}\left[\mathrm{I}_{1}\right][\mathrm{Cat}]
$$

For obtaining the concentration of intermediate $\left[\mathrm{I}_{1}\right]$, the following equation is yielded by applying the steady state assumption:

$$
\begin{gathered}
\frac{\mathrm{d}\left[\mathrm{I}_{1}\right]}{\mathrm{dt}}=k_{1}[\mathbf{1}][2][\mathrm{Cat}]-k_{2}\left[\mathrm{I}_{1}\right][\mathrm{Cat}]=0, \\
{\left[\mathrm{I}_{1}\right]=\frac{k_{1}[\mathbf{1}][2]}{k_{2}} .}
\end{gathered}
$$

And with the replacement of (IX) in (VIII), the following equation is obtained:

$$
\text { rate }=k_{1}[1][2][\text { Cat }] .
$$

The final equation (IX) indicates that the overall order of the reaction is two, additionally, in accordance with this equation; the order of reaction with respect to each compound $(\mathbf{1}, \mathbf{2}$, and 3 ) is 1,1 , and zero, respectively, which was previously confirmed by the experimental data. Due to the presence of $k_{1}$ in the rate low (IX), it is obvious that first step $\left(k_{1}\right)$ is a rate determining step. In this case, the transition state (see step 1, Figure 11) in reaction carries a dispersed charge, effect of solvent (mixture of water and ethanol, 50\%: 50\%), which has higher dielectric constant $(\varepsilon=52.12)$ rather than a mixture of water and methanol (20:80) (with lower dielectric constant $\varepsilon=42.08)$ on this dispersed charge which would be much stronger compared to that on reactants (2 and 1) that do not have any charge. The solvent thus stabilizes the species at the transition state more than it does the reactants, and therefore $E_{a}$ would be lower and speeding up the reaction rate (see Table 1, effect of both solvents). With respect to (IX) $k_{1}$ is proportional to the overall reaction rate; therefore, the activation parameters which involve $\Delta G^{\ddagger}, \Delta S^{\ddagger}$, and $\Delta H^{\ddagger}$ can be now calculated for the first step (rate determining step, $k_{1}$ ), as an elementary reaction, on the basis of Eyring equation. The results are accumulated in Tables 2 and 3.

3.3. Effect of Catalyst. Under similar conditions with previous experiments, the reactions between $\mathbf{1}, \mathbf{2}$, and $\mathbf{3}$ were proceeded in the presence of saccharose or maltose as a catalyst. The results show that the reaction rate speeds up in the maltose medium (see Table 4). It seems that maltose with six-membered ring can increase the reaction rate more than the saccharose with five-membered ring; perhaps the considerable and large size of maltose ring creates more room for easier interactions between the hydroxyl groups with both reactants 1 and 2 (see step 1, Figure 12). 


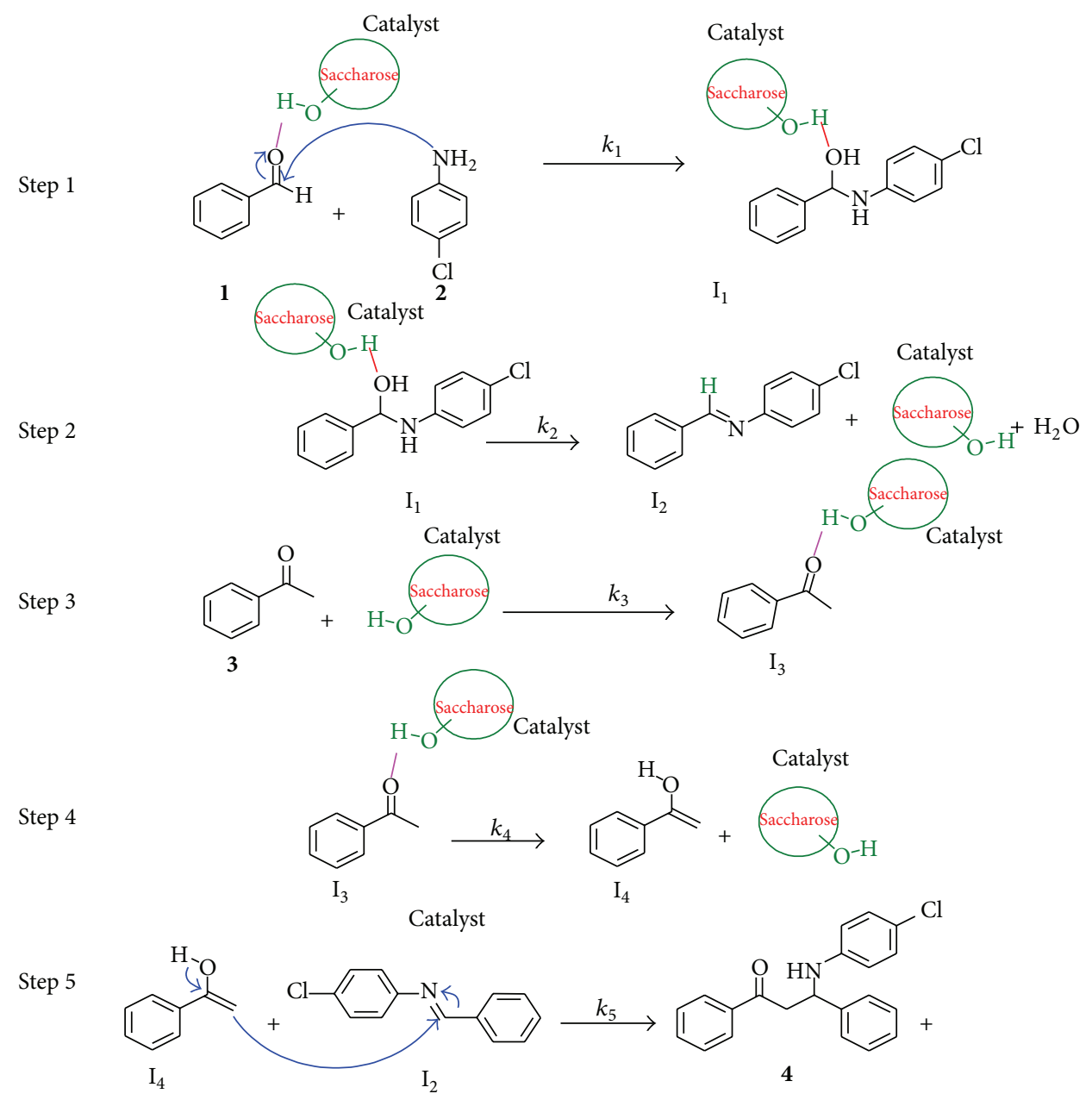

FIGURE 12: The proposed mechanism of the reaction between 1, 2, and 3 for generation of 3-(4-chlorophenylamino)-1,3-diphenylpropan-1-one (4) [33].

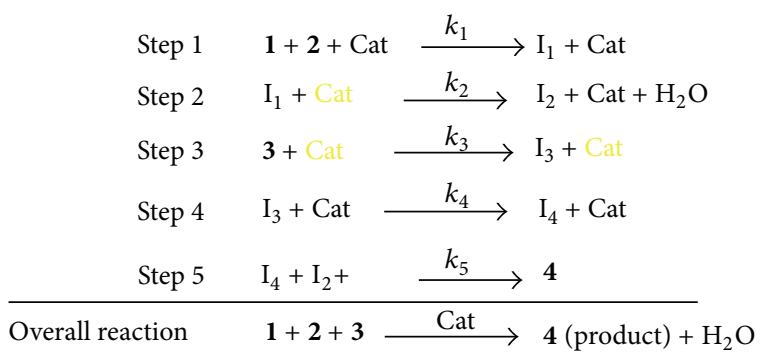

FIGURE 13: Simplified Figure 12 for the proposed reaction mechanism [33].

\section{Conclusions}

In this work, we report an efficient kinetics study for the various conditions. This method has several advantages including mild reaction conditions, operational simplicity, high yields, clean and neutral reaction conditions, and no environmental pollution, and also is an attractive process for the synthesis of $\beta$-aminoketone. Kinetic investigation of the recent reaction
TABLE 2: The dependence of the second order rate constant of the reactions $(\mathbf{1}, \mathbf{2}$, and $\mathbf{3})$ on temperature.

\begin{tabular}{lcccccc}
\hline$k$ & $T$ & $\ln k$ & $k / T$ & $\ln k / T$ & $1 / T$ & $1000 / T$ \\
\hline 3685 & 293.15 & 8.21 & 12.57 & 2.53 & 0.003411 & 3.411 \\
4974 & 298.15 & 8.51 & 16.68 & 2.81 & 0.003354 & 3.354 \\
6264 & 303.15 & 8.74 & 20.66 & 3.03 & 0.003299 & 3.298 \\
7553 & 308.15 & 8.93 & 24.51 & 3.20 & 0.003245 & 3.245 \\
\hline
\end{tabular}

TABLE 3: The activation parameters involving $\Delta G^{\ddagger}, \Delta S^{\ddagger}$, and $\Delta H^{\ddagger}$ for the reactions between $\mathbf{1}, \mathbf{2}$, and $\mathbf{3}$ in a mixture of ethanol and water $(1: 1)$ at $375 \mathrm{~nm}$ and $298.15 \mathrm{~K}$.

\begin{tabular}{lccc}
\hline Reaction & $\Delta G^{\ddagger}\left(\mathrm{kJ} \cdot \mathrm{mol}^{-1}\right)$ & $\Delta H^{\ddagger}\left(\mathrm{kJ} \cdot \mathrm{mol}^{-1}\right)$ & $\Delta S^{\ddagger}\left(\mathrm{kJ} \cdot \mathrm{mol}^{-1} \cdot \mathrm{K}^{-1}\right)$ \\
\hline $\mathbf{1}, \mathbf{2}$ and $\mathbf{3}$ & 16.44 & 597.84 & 1.95 \\
${ }^{\ddagger}$ Transition state. & &
\end{tabular}

was undertaken using UV spectrophotometry. The obtained results can be stated as follows.

(1) The overall order of the reaction followed second order kinetics and the reaction orders each of 
TABLE 4: Effect of catalyst under the same conditions for reaction between 1, 2, and 3 in a mixture of ethanol and water $(1: 1)$ at $375 \mathrm{~nm}$ and $298.15 \mathrm{~K}$.

\begin{tabular}{lcc}
\hline Reaction & Catalyst & $k_{1} \times 10^{-2}\left(\mathrm{~min}^{-1} \cdot \mathrm{M}^{-1}\right)$ \\
\hline $\mathbf{1}, \mathbf{2}$ and $\mathbf{3}$ & Maltose & 56.30 \\
$\mathbf{1 , 2}$ and $\mathbf{3}$ & Saccharose & 49.74 \\
\hline
\end{tabular}

the reactants involving benzaldehyde 1, 4chloroaniline $\mathbf{2}$, and acetophenone $\mathbf{3}$ as one, one, and zero, respectively.

(2) The reaction rate was increased in the presence of solvent with higher dielectric constants reaction rate.

(3) Based on the experimental data, the first step of suggested mechanism was identified as a ratedetermining step $\left(k_{1}\right)$ and this was confirmed by the steady state assumption.

(4) The activation parameters $\Delta G^{\ddagger}, \Delta S^{\ddagger}$, and $\Delta H^{\ddagger}$ have been calculated for the reaction.

(5) The reaction rate was sped up in the presence of a green catalyst with a considerable and large size of flexible ring.

\section{Conflict of Interests}

The authors declare that there is no conflict of interests regarding the publication of this paper.

\section{Acknowledgment}

The authors sincerely thank the University of Sistan and Baluchestan for providing financial support of this work.

\section{References}

[1] M. Arend, B. Westermann, and N. Risch, "Modern variants of the Mannich reaction," Angewandte Chemie, vol. 37, no. 8, pp. 1045-1070, 1998.

[2] R. Müller, H. Goesmann, and H. Waldmann, "N,Nphthaloylamino acids as chiral auxiliaries in asymmetric Mannich-type reactions," Angewandte Chemie, vol. 38, no. 1-2, pp. 184-187, 1999.

[3] S. Kobayashi and H. Ishitani, "Catalytic enantioselective addition to imines," Chemical Reviews, vol. 99, no. 5, pp. 1069-1094, 1999.

[4] T. Akiyama, K. Matsuda, and K. Fuchibe, "HCl-catalyzed stereoselective Mannich reaction in $\mathrm{H}_{2} \mathrm{O}$-SDS system," Synlett, no. 2, pp. 322-324, 2005.

[5] W. B. Yi and C. Cai, "Mannich-type reactions of aromatic aldehydes, anilines, and methyl ketones in fluorous biphase systems created by rare earth (III) perfluorooctane sulfonates catalysts in fluorous media," Journal of Fluorine Chemistry, vol. 127, no. 11, pp. 1515-1521, 2006.

[6] R. Wang, B. G. Li, T. K. Huang, L. Shi, and X. X. Lu, " $\mathrm{NbCl}_{5}$ catalyzed one-pot Mannich-type reaction: three component synthesis of $\beta$-amino carbonyl compounds," Tetrahedron Letters, vol. 48, no. 12, pp. 2071-2073, 2007.
[7] L. Wang, J. Han, J. Sheng, H. Tian, and Z. Fan, "Rare earth perfluorooctanoate $\left[\mathrm{RE}(\mathrm{PFO})_{3}\right]$ catalyzed one-pot Mannich reaction: three component synthesis of $\beta$-amino carbonyl compounds," Catalysis Communications, vol. 6, no. 3, pp. 201204, 2005.

[8] S. Sahoo, T. Joseph, and S. B. Halligudi, "Mannich reaction in Brönsted acidic ionic liquid: a facile synthesis of $\beta$-amino carbonyl compounds," Journal of Molecular Catalysis A: Chemical, vol. 244, no. 1-2, pp. 179-182, 2006.

[9] M. A. Bigdeli, F. Nemati, and G. H. Mahdavinia, " $\mathrm{HClO}_{4}-\mathrm{SiO}_{2}$ catalyzed stereoselective synthesis of $\beta$-amino ketones via a direct Mannich-type reaction," Tetrahedron Letters, vol. 48, no. 38, pp. 6801-6804, 2007.

[10] M. Wu, H. Jing, and T. Chang, "Synthesis of $\beta$-amino carbonyl compounds via a Mannich reaction catalyzed by SalenZn complex," Catalysis Communications, vol. 8, no. 12, pp. 22172221, 2007.

[11] M. Kidwai, D. Bhatnagar, N. K. Mishra, and V. Bansal, "CAN catalyzed synthesis of $\beta$-amino carbonyl compounds via Mannich reaction in PEG," Catalysis Communications, vol. 9, no. 15, pp. 2547-2549, 2008.

[12] G. P. Lu and C. Cai, "Mannich reactions catalyzed by perchloric acid in Triton X10 aqueous micelles," Catalysis Communications, vol. 11, no. 8, pp. 745-748, 2010.

[13] Y. Dai, B. D. Li, H. D. Quan, and C. X. Lu, " $\mathrm{CeCl}_{3} \cdot 7 \mathrm{H}_{2} \mathrm{O}$ as an efficient catalyst for one-pot synthesis of $\beta$-amino ketones by three-component Mannich reaction," Chinese Chemical Letters, vol. 21, no. 1, pp. 31-34, 2010.

[14] H. Wu, X. M. Chen, Y. Wan et al., "Stereoselective Mannich reactions catalyzed by Tröger's base derivatives in aqueous media," Tetrahedron Letters, vol. 50, no. 9, pp. 1062-1065, 2009.

[15] P. Phukan, D. Kataki, and P. Chakraborty, "Direct synthesis of Cbz-protected $\beta$-amino ketones by iodine-catalyzed threecomponent condensation of aldehydes, ketones and benzyl carbamate," Tetrahedron Letters, vol. 47, no. 31, pp. 5523-5525, 2006.

[16] X. C. Wang, L. J. Zhang, Z. Zhang, and Z. J. Quan, "PEG-OSO $3 \mathrm{H}$ as an efficient and recyclable catalyst for the synthesis of $\beta$ amino carbonyl compounds via the Mannich reaction in PEGH 2O," Chinese Chemical Letters, vol. 23, no. 4, pp. 423-426, 2012.

[17] Y. S. Wu, J. Cai, Z. Y. Hu, and G. X. Lin, "A new class of metalfree catalysts for direct diastereo- and regioselective Mannich reactions in aqueous media," Tetrahedron Letters, vol. 45, no. 48, pp. 8949-8954, 2004.

[18] Y. Y. Yang, W. G. Shou, and Y. G. Wang, "Synthesis of $\beta$ amino carbonyl compounds via a $\mathrm{Zn}(\mathrm{OTf})_{2}$-catalyzed cascade reaction of anilines with aromatic aldehydes and carbonyl compounds," Tetrahedron, vol. 62, no. 43, pp. 10079-10086, 2006.

[19] U. Sankappa Rai, A. M. Isloor, P. Shetty, N. Isloor, S. Malladi, and H. K. Fun, "Synthesis and biological evaluation of aminoketones," European Journal of Medicinal Chemistry, vol. 45, no. 12, pp. 6090-6094, 2010.

[20] R. I. Kureshy, S. Agrawal, S. Saravanan et al., "Direct Mannich reaction mediated by $\mathrm{Fe}(\mathrm{Cp})_{2} \mathrm{PF}_{6}$ under solvent-free conditions," Tetrahedron Letters, vol. 51, no. 3, pp. 489-494, 2010.

[21] C. Mukhopadhyay, A. Datta, and R. J. Butcher, "Highly efficient one-pot, three-component Mannich reaction catalysed by boric acid and glycerol in water with major 'syn'diastereoselectivity," Tetrahedron Letters, vol. 50, no. 29, pp. 4246-4250, 2009. 
[22] M. Kidwai, N. K. Mishra, V. Bansal, A. Kumar, and S. Mozumdar, "Novel one-pot Cu-nanoparticles-catalyzed Mannich reaction," Tetrahedron Letters, vol. 50, no. 12, pp. 1355-1358, 2009.

[23] C. T. Chang, B. S. Liao, and S. T. Liu, "Mannich-type reactions in a colloidal solution formed by sodium tetrakis $(3,5-$ trifluoromethylphenyl)borate as a catalyst in water," Tetrahedron Letters, vol. 47, no. 52, pp. 9257-9259, 2006.

[24] C. B. Yue, T. F. Yi, C. B. Zhu, and G. Liu, "Mannich reaction catalyzed by a novel catalyst under solvent-free conditions," Journal of Industrial and Engineering Chemistry, vol. 15, no. 5, pp. 653-656, 2009.

[25] R. K. Sharma, D. Rawat, and G. Gaba, "Inorganic-organic hybrid silica based tin(II) catalyst: synthesis, characterization and application in one-pot three-component Mannich reaction," Catalysis Communications, vol. 19, pp. 31-36, 2012.

[26] T. P. Loh, S. B. K. W. Liung, K. L. Tan, and L. L. Wei, “Three component synthesis of $\beta$-amino carbonyl compounds using indium trichloride-catalyzed one-pot Mannich-type reaction in water," Tetrahedron, vol. 56, no. 20, pp. 3227-3237, 2000.

[27] K. Manabe, Y. Mori, and S. Kobayashi, "Three-component carbon-carbon bond-forming reactions catalyzed by a Brønsted acid-surfactant-combined catalyst in water," Tetrahedron, vol. 57, no. 13, pp. 2537-2544, 2001.

[28] M. L. Kantam, C. V. Rajasekhar, G. Gopikrishna, K. Rajender Reddy, and B. M. Choudary, "Proline catalyzed twocomponent, three-component and self-asymmetric Mannich reactions promoted by ultrasonic conditions," Tetrahedron Letters, vol. 47, no. 33, pp. 5965-5967, 2006.

[29] Y. C. Teo, J. J. Lau, and M. C. Wu, "Direct asymmetric threecomponent Mannich reactions catalyzed by a siloxy serine organocatalyst in water," Tetrahedron Asymmetry, vol. 19, no. 2, pp. 186-190, 2008.

[30] N. Saadatjoo, M. Golshekan, S. Shariati, P. Azizi, and F. Nemati, "Ultrasound-assisted synthesis of $\beta$-amino ketones via a Mannich reaction catalyzed by $\mathrm{Fe}_{3} \mathrm{O}_{4}$ magnetite nanoparticles as an efficient, recyclable and heterogeneous catalyst," Arabian Journal of Chemistry, 2012.

[31] R. Mahrwald, "Organocatalytic methods for CC bond formation,” Drug Discovery Today: Technologies, vol. 10, no. 1, pp. e29e36, 2013.

[32] S. S. Sajadikhah, M. T. Maghsoodlou, N. Hazeri, S. M. HabibiKhorassani, and A. C. Willis, "One-pot five-component synthesis of highly functionalized piperidines using oxalic acid dihydrate as a homogenous catalyst," Chinese Chemical Letters, vol. 23, no. 5, pp. 569-572, 2012.

[33] M. R. Mousavi, N. Hazeri, M. T. Maghsoodlou, S. Salahi, and S. M. Habibi-Khorassani, "Entirely green protocol for the synthesis of $\beta$-aminoketones using saccharose as a homogenous catalyst," Chinese Chemical Letters, vol. 24, no. 5, pp. 411-414, 2013.

[34] O. J. Nielsen, J. Sehested, S. Langer, E. Ljungström, and I. Wängberg, "UV absorption spectra and kinetics for alkyl and alkyl peroxy radicals originating from di-tert-butyl ether," Chemical Physics Letters, vol. 238, pp. 359-364, 1995.

[35] S. Langer, E. Ljungström, T. Ellermann, O. J. Nielsen, and J. Sehested, "UV absorption spectrum of $\mathrm{CH}_{3} \mathrm{OCH}_{2}$ radicals and kinetics of the reaction of $\mathrm{CH}_{3} \mathrm{OCH}_{2} \mathrm{O}_{2}$ radicals with $\mathrm{NO}$ and $\mathrm{NO}_{2}$ in the gas phase," Chemical Physics Letters, vol. 240, pp. 53-56, 1995.

[36] V. V. Ivanov and C. Decker, "Kinetic study of photoinitiated frontal polymerization," Polymer International, vol. 50, no. 1, pp. 113-118, 2001.
[37] P. C. Fung, K. M. Sin, and S. M. Tsui, "Decolorisation and degradation kinetics of reactive dye wastewater by a UV/ultrasonic/peroxide system," Journal of the Society of Dyers and Colourists, vol. 116, no. 5-6, pp. 170-173, 2000.

[38] F. Misiti, M. Castagnola, C. Zuppi, B. Giardina, and I. Messana, "Role of ergothioneine on S-nitrosoglutathione catabolism," Biochemical Journal, vol. 356, no. 3, pp. 799-804, 2001.

[39] M. Shahraki, S. M. H. Khorassani, A. Ebrahimi, M. T. Maghsoodlou, and A. Paknahad, "Theoretical, kinetic and mechanistic studies of the reaction between dialkyl acetylenedicarboxylates, triphenylphosphine and pyrrole in organic solvents," Progress in Reaction Kinetics and Mechanism, vol. 37, no. 4, pp. 321-343, 2012.

[40] S. M. Habibi-Khorassani, M. T. Maghsoodlou, M. Zakarianezhad, M. Nassiri, M. A. Kazemian, and P. Karimi, "A facile synthesis of stable phosphorus ylides derived from 3,6dibromocarbazole and kinetic investigation of the reactions by UV spectrophotometry technique," Heteroatom Chemistry, vol. 19, no. 7, pp. 723-732, 2008.

[41] S. M. Habibi-Khorassani, A. Ebrahimi, M. T. Maghsoodlou et al., "Theoretical study, an efficient synthesis route to, and kinetic investigation of, stable phosphorus ylides derived from benzamide," Progress in Reaction Kinetics and Mechanism, vol. 34, no. 3, pp. 261-288, 2009.

[42] S. M. Habibi Khorassani, M. T. Maghsoodlou, A. Ebrahimi, M. Zakarianejad, and M. Fattahi, "Kinetics and mechanism of the reactions between triphenylphosphine, dialkyl acetylenedicarboxilates and a NH-acid, pyrazole, by UV spectrophotometry," Journal of Solution Chemistry, vol. 36, no. 9, pp. 1117-1127, 2007.

[43] S. M. H. Khorassani, M. T. Maghsoodlou, E. Aghdaei, and M. Shahraki, "1H NMR technique for kinetic investigation of equilibrium between the Z- and E-isomers in a stable phosphorus ylide involving a 2-indolinone," Progress in Reaction Kinetics and Mechanism, vol. 37, no. 3, pp. 301-310, 2012.

[44] M. A. Kazemian, P. Karimi, S. M. Habibi-Khorassani, A. Ebrahimi, M. T. Maghsoodlou, and F. J. Milani, "Synthesis of stable phosphorus ylides from 6-chloro-2-benzoxazolinone and kinetic investigation of the reactions by uv spectrophotometry," Progress in Reaction Kinetics and Mechanism, vol. 34, no. 1, pp. 77-96, 2009.

[45] S. M. Habibi Khorassani, M. T. Maghsoodlou, A. Ebrahimi, M. Zakarianejad, P. Mojhammadzadeh, and M. Shahraki, "Kinetic study and mechanism investigation of the reactions between triphenylphosphine, dialkyl acetylene dicarboxylates and $\mathrm{NH}$ acid such as Harman," Oriental Journal of Chemistry, vol. 24, no. 1, pp. 73-82, 2008.

[46] S. M. Habibi-Khorassani, A. Ebrahimi, M. T. Maghsoodlou, M. Zakarianezhad, H. Ghasempour, and Z. Ghahghayi, “Theoretical, nmr study, kinetics and a mechanistic investigation of the reaction between triphenylphosphine, dialkyl acetylenedicarboxylates and 2-aminothiophenol," Current Organic Chemistry, vol. 15, no. 6, pp. 942-952, 2011.

[47] R. Kabiri, N. Hazeri, S. M. Habibi Khorassani et al., "Synthesis, dynamic $1 \mathrm{H}$ NMR and theoretical study of aryl-nitrogen single bond rotational energy barriers in highly functionalized $4 \mathrm{H}$ chromenes," Arkivoc, vol. 2008, no. 17, pp. 12-19, 2008.

[48] L. M. Schwartz and R. I. Gelb, "Alternative method of analyzing first-order kinetic data," Analytical Chemistry, vol. 50, no. 11, pp. 1592-1594, 1978. 

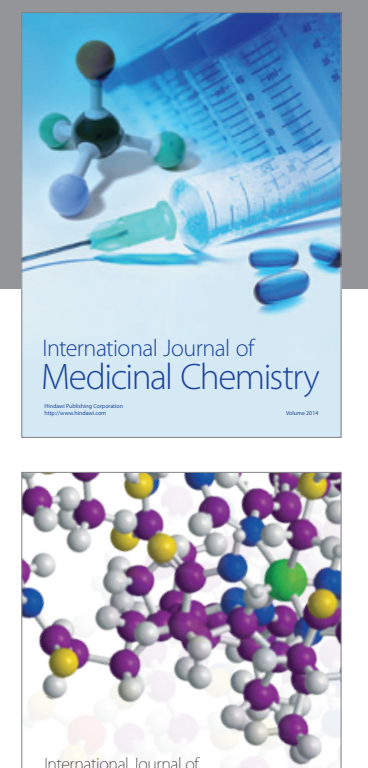

\section{Carbohydrate} Chemistry

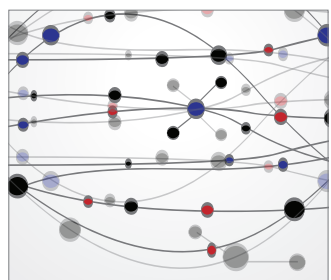

The Scientific World Journal
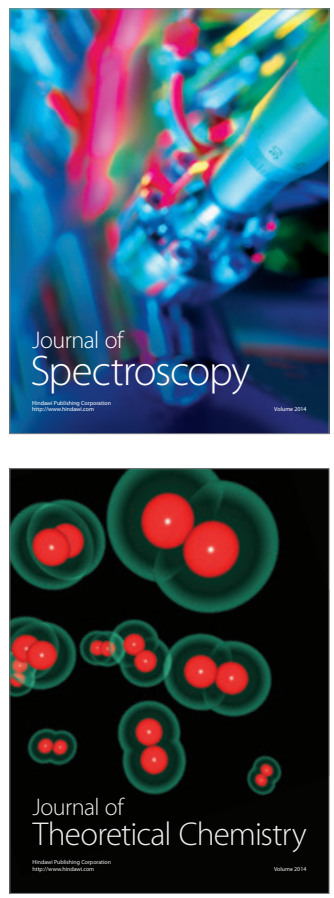
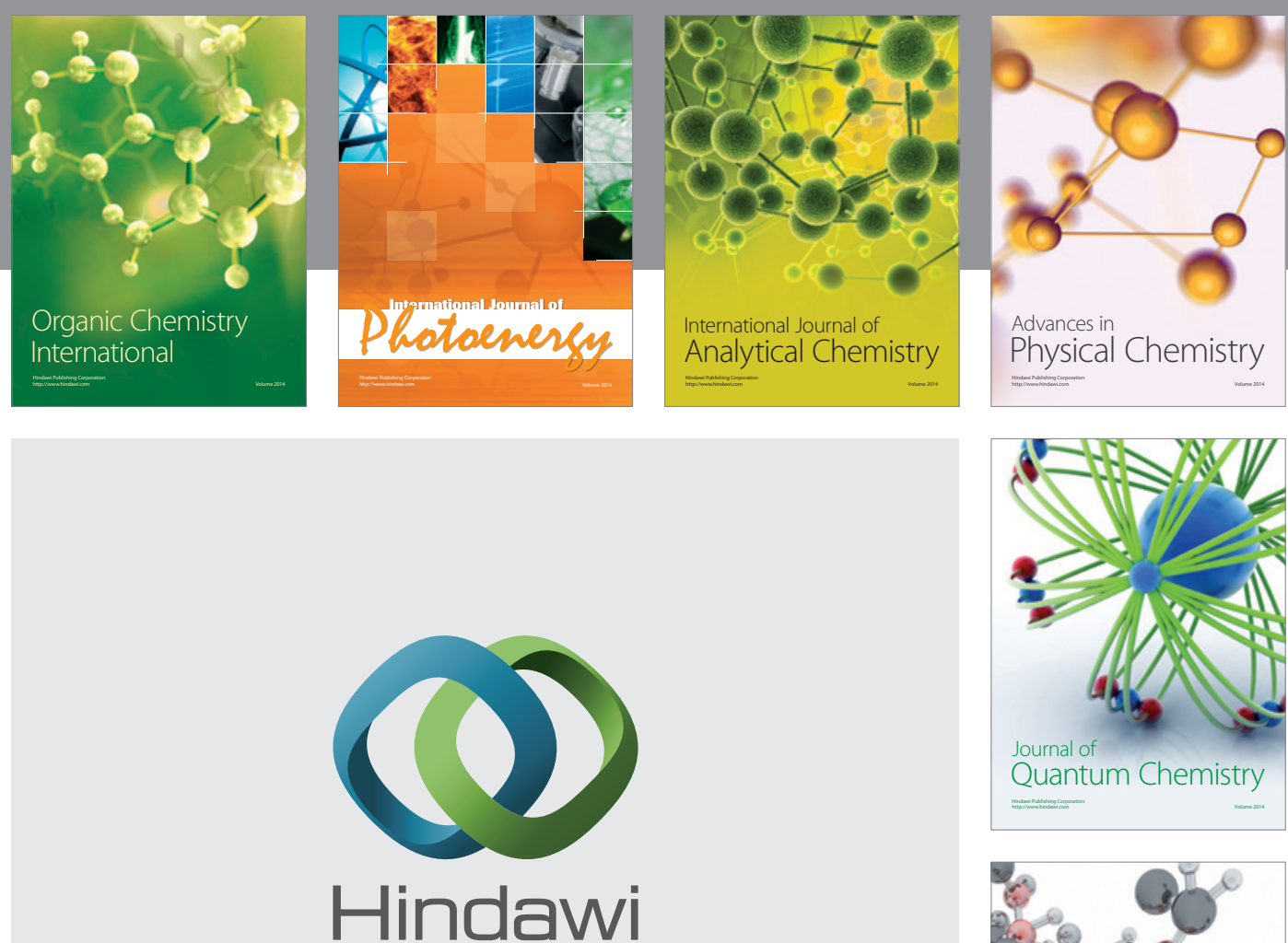

Submit your manuscripts at

http://www.hindawi.com

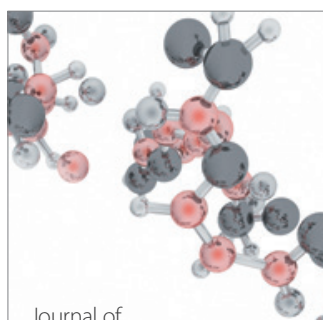

Analytical Methods

in Chemistry

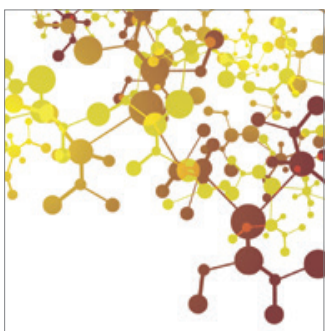

Journal of

Applied Chemistry

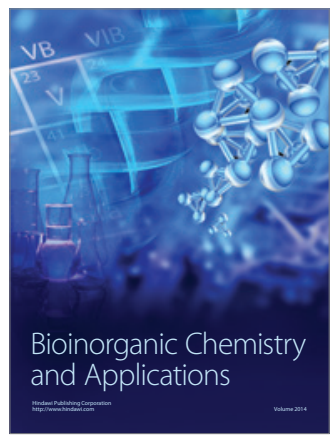

Inorganic Chemistry
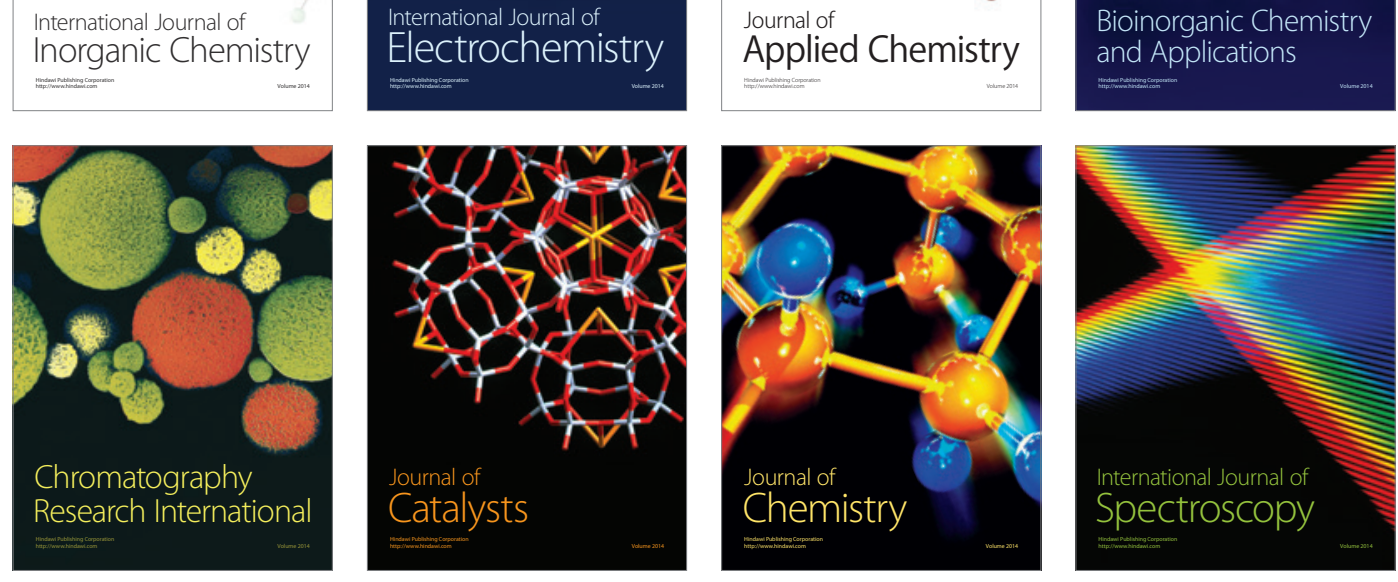